\title{
Recurrent Miscarriage: Hysteroscopy-Assisted Management
}

\author{
Fady M. Shawky Moiety*, Abdel Fattah Agameya, Hisham Aly Saleh \\ Department of Obstetrics and Gynecology, Faculty of Medicine, Alexandria University, Alexandria, Egypt \\ Email: *fmoiety@gmail.com
}

How to cite this paper: Moiety, F.M.S., Agameya, A.F. and Saleh, H.A. (2018) Recurrent Miscarriage: Hysteroscopy-Assisted Management. Open Journal of Obstetrics and Gynecology, 8, 425-430. https://doi.org/10.4236/ojog.2018.85048

Received: December 21, 2017

Accepted: May 1, 2018

Published: May 4, 2018

Copyright ( $) 2018$ by authors and Scientific Research Publishing Inc. This work is licensed under the Creative Commons Attribution International License (CC BY 4.0).

http://creativecommons.org/licenses/by/4.0/

(c) (i) Open Access

\begin{abstract}
Objective: To apply office hysteroscopy in assessment/management of patients with recurrent miscarriage, thus to/or not to recommend office hysteroscopy as a routine procedure in such cases. Study design: Retrospective analysis. Setting: University hospital's outpatient abortion clinic. Subjects \& Methodology: Patients' records during the period between March 2015 and January 2017 for subjects with at least 2 previous miscarriages, who had undergone office hysteroscopy were reviewed. Results: Cases with 2 previous miscarriages $(n=95)$ were assessed and compared with those with 3 or more miscarriages $(n=105)$. Abnormal uterine findings were diagnosed in $24.1 \%$ of the former, and $43.8 \%$ of the latter group. The prevalence of uterine lesions among cases with 2 recurrent miscarriages was $42.1 \%$; meanwhile, for subjects with 3 or more consecutive miscarriages, it was $43.8 \%$. Conclusion: In addition to safety profile, simplicity and outpatient basis of use, outpatient hysteroscopy in recurrent miscarriages would be an added-value to practitioners as a diagnostic and therapeutic tool.
\end{abstract}

\section{Keywords}

Hysteroscopy, Office, Recurrent, Miscarriage

\section{Introduction}

By definition, 3 pregnancy terminations in a row before 20 weeks, is termed recurrent pregnancy loss [1]. Some couples, however would start seeking a professional advice, and investigating recurrent miscarriages after the second pregnancy loss, as thought to be helping detect the cause early enough to treat. However, this has not been shown beneficial [2]. Uterine abnormalities, are implicated as one of the causes of recurrent miscarriages, and have been estimated to be diagnosed in as many as $10 \%$ to $15 \%$ of patients with repeated miscarriag- 
es. Exclusion of any intrauterine pathology is an important step before subjecting the patient to another pregnancy at risk [3]. Hysterosalpingogram (HSG) has classically been used to assess the uterine cavity for defects, Sonohysterography could be also used with more information on endometrial lesions, however, hysteroscopy, the gold standard for evaluating the uterine cavity, can be performed reliably and safely as an office, minimally invasive procedure [4]. The role of hysteroscopy is to detect possible intrauterine changes that could interfere with implantation or growth, or both, of the conceptus [5]. However the hysteroscopy is still an invasive procedure and its role in routine management of recurrent miscarriages is to be evaluated. Other tests for recurrent pregnancy loss may include investigating parental genetic disorders, thrombophilias, and maternal hormonal dysfunction [2]. The aim of this study was to test the application of office hysteroscopy in assessment/management of patients with recurrent miscarriage, thus to/or not to recommend it as a routine procedure in such cases.

\section{Subjects and Methodology}

This retrospective study included patients' medical record during the period between March 2015 and January 2017, at Shat by-Alexandria University hospital's, recurrent miscarriage clinic. To be included, each record must confirm having two or more consecutive pregnancy losses before completing 20 weeks of gestation. In addition, having undergone an office hysteroscopy on outpatient basis under the care of the first author. Subjects with history of chromosomal defects, endocrinopathies, or thrombophilias were excluded. Office hysteroscopy $(\mathrm{OH})$ was performed, using A2.9 mm semi-rigid hysteron scope (Gynecare, Ethicon, USA $\left.{ }^{\circledR}\right)$. Distention of the uterine cavity was accomplished with normal saline solution. The procedure was considered complete only when the entireuterine cavity and both Tubal Ostia were visualized. Reports of 3D Ultrasonographic scans, done after the procedure, and confirming the diagnosis of uterine lesion if any, were also reviewed. Statistical Analysis was perform educing the Student's $t$-test. A result of $P \leq 0.05$ was considered significant.

\section{Results}

The total number of patients fulfilling the inclusion criteria was 200. Cases with 2 previous miscarriages $(n=95)$ were assessed and compared with those with 3 or more miscarriages $(n=105)$, where no significant differences were found between both groups in terms of age, parity, or body mass index (BMI). The number of cases with more than 3 miscarriages was 18 cases. Abnormal uterine findings were diagnosed in $24.1 \%$ of the former, and $43.8 \%$ of the latter group. No statistically significant difference was seen between the 2 groups regarding the type and incidence of uterine lesions, except submucus fibroids, being significantly more frequent in the $2^{\text {nd }}$ group. The prevalence of uterine lesions among cases with 2 recurrent miscarriages was $42.1 \%$ (22.1\% Acquired, and 20\% congenital), meanwhile, for subjects with 3 or more consecutive miscarriages, it 
was $43.8 \%$ (31.4\% Acquired, and 12.4\% congenital) (Table 1, Figure 1).The duration of $\mathrm{OH}$ procedure ranged from 10 - 15 minutes. The procedure was acceptable in almost all patients. The majority of the patients did not feel any significant pain during the procedure; and all were discharged within 30 minutes after the procedure, without any reported complications.

\section{Discussion}

One of the basic steps of workup for recurrent pregnancy loss is to evaluate the shape and regularity of the uterine cavity [6]. After 2 consecutive miscarriages,

Table 1. Hysteroscopic findings in 200 subjects with recurrent pregnancy loss.

\begin{tabular}{cccc}
\hline Findings & $\begin{array}{c}\text { Two pregnancy } \\
\text { losses }(\mathrm{n}=95)(\%)\end{array}$ & $\begin{array}{c}\text { Three or more pregnancy } \\
\text { losses }(\mathrm{n}=105)(\%)\end{array}$ & $P$ Value \\
\hline Normaluterinecavity & $55(57.9)$ & $59(56.2)$ & NS \\
Abnormal intrauterine finding & $40(42.1)$ & $46(43.8)$ & NS \\
Acquired Finding & $21(22.1)$ & $33(31.4)$ & NS \\
Submucous fibroid - & 0 & 5 & $<0.04^{*}$ \\
Endometrial polyp & 8 & 5 & NS \\
Multiple focal findings & 4 & 5 & NS \\
Intrauterine adhesions & 4 & 5 & NS \\
Cervical polyp & 0 & 3 & NS \\
Endometritis & 2 & 2 & NS \\
Blocked Ostia & 3 & 2 & NS \\
Congenital Malformation & $19(20)$ & $13(12.4)$ & NS \\
Uterine septum & 17 & 13 & NS \\
Ashermansyndrome & 2 & 0 & \\
Total & 95 & 105 & \\
\hline
\end{tabular}

*: Statistically significant at $p \leq 0.05$. NS: Not significant.

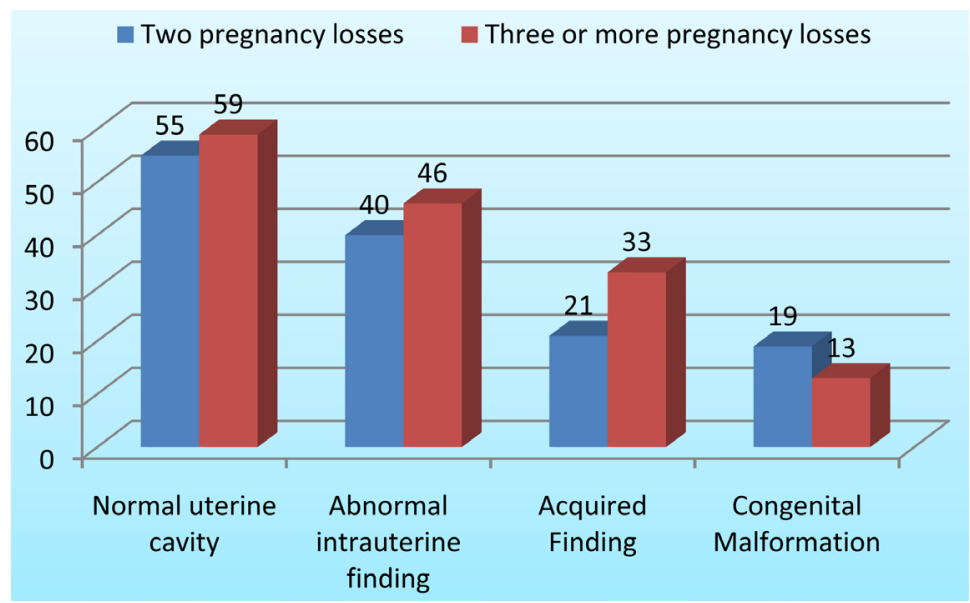

Figure 1. Comparison between the 2 groups in terms of uterine finding on $\mathrm{OH}$. 
the patient would usually start to seek medical assistance, not waiting for a third "round" that would be highly probable, thus a suggestion has been made to modify the original definition, and accept 2 consecutive spontaneous pregnancy losses instead of 3 to fulfill the definition [7]. In this work, we studied a representative sample of patients with recurrent miscarriage (200 patients), which is, to our knowledge, the largest number studied for such an uncommon condition. A similar study by Ventolini G. et al., for instance, was conducted on only 23 patients [8]. Another published work by Dendrinos S. et al. reported 48 patients with 3 consecutive miscarriages without dividing them into groups [9].

Our results demonstrated that the prevalence of uterine lesions among cases with 2 recurrent miscarriages was $42.1 \%$ (22.1\% Acquired, and 20\% congenital), meanwhile, for subjects with 3 or more consecutive miscarriages, it was 43.8 (31.4\% Acquired, and $12.4 \%$ congenital). A prevalence of uterine anomalies causing recurrent abortion was reported to vary between $15 \%$ - 27\% [10] [11] [12], and up to $50 \%$ by Keltz et al. [13] The variable number of recruits and the different design of each research could be the cause of such vast variation.

Portuondo et al., also compared cases with 2 or 3 recurrent miscarriages, in terms of uterine abnormalities using HSG, and found no difference [14]. We confirmed the diagnosis of uterine Müllerian anomalies using a 3D ultrasonographic scan. This was also reported by Raga F. et al. and Wu MH et al. [15] [16]. The European Society of Human Reproduction and Embryology (ESHRE) guidelines indicate hysteroscopy may be only necessary, for the confirmation and treatment of doubtful intrauterine pathology [17]. In the current study, Assessment of the uterine cavity in patients with recurrent pregnancy loss was the main indication for performing diagnostichysteroscopy. It appears that many patients interpreted as normal following a HS Gare found to have a uterine abnormality after diagnostichysteroscopy, which might be a sign if I cant cause of reproductive failure [6].

Donnez and Jadoul concluded that those uterine anomalies do influence pregnancy course [18]. Office hysteroscopy allows complete, accurate identification of intrauterine abnormalities that might negatively affect pregnancy continuation. We identified 11 cases with intrauterine adhesions using office hysteroscopy in this series. All of those cases were managed by hysteroscopicadhesiolysis, which would help improve their pregnancy outcome. Valli et al., also concluded that the role of hysteroscopy in lysing the intrauterine adhesions would improve pregnancy outcome in patients having recurrent miscarriages [19]. In concordance, Bouet PE et al. confirmed that office hysteroscopy is a useful tool in the management of women with recurrent pregnancy loss, preferably when complemented by a biopsy from the endometrium to diagnose chronic endometritis [20]. Dendrinos S. et al. also stated that hysteroscopy is superior to HSG for identification of intrauterine pathology, thus being a reliable assessment tool of the uterine cavity with a high specificity and sensitivity [9].

In our work, office hysteroscopy was very acceptable by patients with ex- 
tremely high safety profile and significant diagnostic potential on any intrauterine lesion. The large number of subjects studied, and the considerable amount of data obtained on each, are good points of strength adding to the value of this research. A weak point, however, is its retrospective type.

\section{Conclusion}

We justify the introduction of office hysteroscopy in the routine work-up of cases with recurrent miscarriages. Intervention after 2 miscarriages would be more beneficial, based on the high incidence of uterine anomalies detected in this work, most of which were missed by other diagnostic modalities. We also confirm a good safety profile, acceptability and outstanding diagnostic potential of office hysteroscopy.

\section{Acknowledgements}

The authors wish to thank the University of Alexandria for their support during most of the steps of this study.

\section{Conflict of Interest}

There has been no conflict of interest of any kind with the authors of this work.

\section{References}

[1] Li, T.C., Makris, M., Tomsu, M., Tuckerman, E. and Laird, S. (2002) Recurrent Miscarriage: Aetiology, Management and Prognosis. Human Reproduction Update, 8, 463-481. https://doi.org/10.1093/humupd/8.5.463

[2] Weiss, A., Shalev, E. and Romano, S. (2005) Hysteroscopy May Be Justified after Two Miscarriages. Human Reproduction, 20, 2628-2631. https://doi.org/10.1093/humrep/dei081

[3] Brown, S.E., Coddington, C.C., Schnorr, J., Toner, J.P., Gibbons, W. and Oehninger, S. (2000) Evaluation of Outpatient Hysteroscopy, Saline Infusion Hysterosonography and Hysterosalpingography in Infertile Women: A Prospective, Randomized Study. Fertility and Sterility, 74, 1029-1034. https://doi.org/10.1016/S0015-0282(00)01541-7

[4] Gordts, S., Campo, R., Puttemans, P., et al. (2002) Investigation of the Infertile Couple. Human Reproduction, 17, 1684-1687. https://doi.org/10.1093/humrep/17.7.1684

[5] Campo, R., Van Belle, Y., Rombauts, L., Brosens, I. and Gordts, S. (1999) Office Mini-Hysteroscopy. Human Reproduction Update, 5, 73-81. https://doi.org/10.1093/humupd/5.1.73

[6] Shushan, A. and Rojansky, N. (1999) Should Hysteroscopy Be a Part of the Basic Infertility Workup? Human Reproduction, 14, 1923-1924. https://doi.org/10.1093/humrep/14.8.1923

[7] Chauhan, S. and Moghissi, K.S. (2002) Recurrent Pregnancy Wastage. Postgraduate Obstetrics \& Gynecology, 22, 1-7.

[8] Ventolini, G., Zhang, M. and Gruber, J. (2004) Hysteroscopy in the Evaluation of Patients with Recurrent Pregnancy Loss: A Cohort Study in a Primary Care Population. Surgical endoscopy, 18, 1782-1784. 
[9] Dendrinos, S., Grigoriou, O., Sakkas, E.G., Makrakis, E. and Creatsas, G. (2008) Hysteroscopy in the Evaluation of Habitual Abortions. The European Journal of Contraception \& Reproductive Health Care, 13, 198-200. https://doi.org/10.1080/13625180801920032

[10] Lee, R.M. and Silver, R.M. (2000) Recurrent Pregnancy Loss: Summary and Clinical Recommendations. Seminars in Reproductive Medicine, 18, 433-440.

[11] Salim, R., Regan, L., Woelfer, B., et al. (2003) A Comparative Study of the Morphology of Congenital Uterine Anomalies in Women with and without a History of Recurrent First Trimester Miscarriage. Human Reproduction, 18, 162-166. https://doi.org/10.1093/humrep/deg030

[12] Traina, E., Mattar, R., Moron, A.F., et al. (2004) Diagnostic Accuracy of Hysterosalpingography and Transvaginal Sonography to Evaluate Uterine Cavity Diseases in Patients with Recurrent Miscarriage. Revista Brasileira De Ginecologia E Obstetricia, 26, 527-533.

[13] Keltz, M.D., Olive, D.L., Kim, A.H. and Arici, A. (1997) Sonohysterography for Screening in Recurrent Pregnancy Loss. Fertility and Sterility, 67, 670-674.

[14] Portuondo, J.A., Camara, M.M., Echanojauregui, A.D. and Calonge, J. (1986) Mullerian Abnormalities in Fertile Women and Recurrent Aborters. The Journal of Reproductive Medicine, 31, 616-619.

[15] Raga, F., Bauset, C., Remohi, J., Bonilla-Musoles, F., Simón, C. and Pellicer, A. (1997) Reproductive Impact of Congenital Müllerian Anomalies. Human Reproduction (Oxford, England), 12, 2277-2281.

[16] Wu, M.H., Hsu, C.C. and Huang, K.E. (1997) Detection of Congenital Müllerian Duct Anomalies using Three Dimensional Ultrasound. Journal of Clinical Ultrasound, 25, 487-492.

[17] Crosignani, P.G. and Rubin, B.L. (2000) Optimal Use of Infertility Diagnostic Tests and Treatments. The ESHRE Capri Workshop Group. Human Reproduction, 15, 723-732.

[18] Donnez, J. and Jadoul, P. (2002) What Are the Implications of Myomas on Fertility? A Need for a Debate? Human Reproduction, 17, 1424-1430.

[19] Valli, E., Vaquero, E., Lazzarin, N., Caserta, D., Marconi, D. and Zupi, E. (2004) Hysteroscopicmetroplasty Improves Gestational Outcome in Women with Recurrent Spontaneous Abortion. The Journal of the American Association of Gynecologic Laparoscopists, 11, 240-244.

[20] Bouet, P.E., El Hachem, H., Monceau, E., Gariépy, G., Kadoch, I.J. and Sylvestre, C. (2016) Chronic Endometritis in Women with Recurrent Pregnancy Loss and Recurrent Implantation Failure: Prevalence and Role of Office Hysteroscopy and Immunohistochemistry in Diagnosis. Fertility and Sterility, 105, 106-110. 